\title{
Human factors and human nature in cardiothoracic surgery
}

\author{
Michael D. Bolanos, Joseph B. Zwischenberger \\ Division of Cardiothoracic Surgery, Department of Surgery, University of Kentucky, Lexington, KY, USA \\ Correspondence to: Joseph B. Zwischenberger, MD. Johnston-Wright Professor and Chairman of Surgery, Professor of Pediatrics, Biomedical \\ Engineering, and Diagnostic Radiology, University of Kentucky College of Medicine, 800 Rose Street, MN264, Lexington, KY 40536-0298, USA. \\ Email: jzwis2@uky.edu. \\ Provenance: This is an invited Editorial commissioned by Executive Editor-in-Chief Jianxing He [The First Affiliated Hospital of Guangzhou \\ Medical University, Guangzhou, Guangdong, China) and the Section Editor Jianfei Shen (Taizhou Hospital of Zhejiang Province, Wenzhou Medical \\ University, Taizhou, China]. \\ Comment on: Fann JI, Moffatt-Bruce SD, DiMaio JM, et al. Human Factors and Human Nature in Cardiothoracic Surgery. Ann Thorac Surg. \\ 2016;101:2059-66.
}

Submitted May 03, 2017. Accepted for publication Jun 23, 2017.

doi: $10.21037 /$ jtd.2017.07.22

View this article at: http://dx.doi.org/10.21037/jtd.2017.07.22

In the June 2016 edition of the Annals of Thoracic Surgery, Fann et al. eloquently outline approaches to minimize factors that may affect cardiothoracic surgical outcomes including minimizing external distractions, improving interpersonal communication and teamwork, and mitigating work-related stress (1). In this article there were parallels drawn between the aviation trade and the cardiothoracic surgical community. This comparison has long been established, and there are inherent similarities including the countless hours needed to perfect their trade, the skill and stamina needed to execute a long flight or case, and situational awareness. However, the differences between the two must also be evaluated.

The complex nature of cardiothoracic surgery often requires a surgeon's undivided attention for prolonged periods of time, which is continuously threatened by internal and external factors. Internally, the surgeon must repeatedly assess his/her ability to carry out the given task despite fatigue. The aviation industry has very strict rules regarding work hours (2). While there are duty hour regulations for surgical trainees (3), the duty hours no longer apply to surgeons at the attending level. Externally, the electronic health record (EHR) will infiltrate the surgeon's day immeasurably. The burden of EHRs (often estimated at $2 \mathrm{~h}$ to 1 relative to patient care) directly affect patient care and physician satisfaction, contributing to physician burnout (4). In contrast to medicine, documentation in aviation plays a minor role in the overall pilot burden. Despite our era of technology, which promised streamlining of EMRs, the focus on patient care has become more difficult as documentation requirements have dramatically increased.

Physician well-being is largely dependent on combating fatigue and minimizing those factors which may contribute to physician burnout. Physician burnout plays a significant role in performance, at both the resident and attending levels (5). Despite awareness, physician burnout continues to increase, as high as $50 \%$, and satisfaction seems to be at an all-time low.

There are numerous recognized strategies for improving physician burnout championed by the Cleveland Clinic (6) and others, particularly as it relates to the problem of EMRs and documentation. Included are: (I) voice recognition for EMR which is about three times faster than typing; (II) hiring more advanced providers and part-time physicians; (III) access to IT desktop support staff; (IV) development of 'tap and go' access that can cut logon time to as little as 5 seconds; (V) streamlining pharmacy refill authorizations; (VI) access to IBM Watson, a computer repository of medical knowledge that can access up to 40 million documents in just 14 seconds; and (VII) improved access to mobile technologies such as a secure cloud and cognitive computing programs that allow differential diagnostic and customized therapeutic pathways.

Fann $e t$ al. also discuss distractions in the operating room and their effects on work flow (1). Minimizing distractions and maximizing the focus of the entire operating room is 
essential to ensure the success of an operation. Steps to combat surgeon fatigue should be implemented. Optimizing modifiable factors such as ergonomics and micro-breaks may play a role in maintaining surgeon focus during long cases minimizing fatigue (7). The quantity and types of distractions can have variable effects. Equipment-related distractions, as well as acoustic distractions, may increase stress levels of circulating nurses and surgeons affecting work flow (8). Strategies to minimize distractions and maintain focus on the patient are paramount, and the entire surgical team should work to reach a consensus.

Overestimation of one's abilities, particularly for surgeons, may create a false sense of security that introduces an avenue for error to occur $(9,10)$. We have noted in case planning the surgeons always have a preoperative perception of case flow, which is then experienced during the case, but only fully appreciated after the case. Simple tasks such as checklists and debriefings require nominal time and effort and create an additional layer of safety. Surgeons, as leaders, must ensure that all staff has a level of comfort to express concerns, ask questions, and address logistical issues.

Similarly, surgeons must be sensitive to the current environment that has been created which provides various "gotcha pathways" for which complaints may be filed and litigation pursued. Long gone are the days by which a surgeon could be reprimanded by the chairman as the sole avenue of disciplinary action. Today, the pathways which may lead to disciplinary action are many and include: (I) Division Chief; (II) Chairman of Surgery; (III) Chief Medical Officer; (IV) Nursing; (V) Human Resources; (VI) Dean of College of Medicine; (VII) Dean of Graduate Medical Education; (VIII) Office of Patient Experience; (IX) Office of Risk Management; (X) Office of Institutional Equity and Equal Opportunity; (XI) Institutional or State credentialing; (XII) Organ Procurement Organizations (OPOs); (XIII) University Provost; and (XIV) Office of Research Integrity. This list does not include litigious pathways. The growing number of pathways by which administration can reprimand surgeons today invariably adds to work-related stress with fear of punitive consequences. Creating a cordial work environment centered on professionalism and respect will encourage surgeons to remain compliant with these pathways.

Duty hours, a shortage in support staff, and the burden of EHRs are clearly contributing to the growing problem of physician burnout. Minimizing external distraction in the OR, involving co-workers in decision making, and maximizing work-flow should be the focus of every cardiothoracic surgeon's practice. Lastly, surgeons should not overestimate their technical or social abilities. They must be acutely aware of the new environment in which we practice, an environment where litigation and disciplinary action is facilitated, not controlled. In an effort to mitigate stress and fear of punitive consequences, surgeons should aim at maintaining a collegial operating room, focused on respect where the staff feels comfortable expressing concerns, voicing opinions, and achieving predictable but adaptive workflow.

\section{Acknowledgements}

None.

\section{Footnote}

Conflicts of Interest: The authors have no conflicts of interest to declare.

\section{References}

1. Fann JI, Moffatt-Bruce SD, DiMaio JM, et al. Human Factors and Human Nature in Cardiothoracic Surgery. Ann Thorac Surg 2016;101:2059-66.

2. Electronic Code of Federal Regulations. US Government Publishing Office website. Available online: https://www. ecfr.gov/cgi-bin/text-idx? node=14:2.0.1.3.10 [Accessed April 30, 2017].

3. Accreditation Council for Graduate Medical Education (ACGME). Common Program Requirements Section VI - Tracked Changes. ACGME approved major revision of Section VI February, 2017; effective: July 1, 2017.

ACGME website. Available online: https://www.acgme.org/ Portals/0/PFAssets/ReviewandComment/CPR_SectionVI_ ImpactStatement.pdf [Accessed April 30, 2017].

4. Rao SK, Kimball AB, Lehrhoff SR, et al. The impact of administrative burden on academic physicians: results of a hospital-wide physician survey. Acad Med 2017;92:237-43.

5. Dyrbye LN, Varkey P, Boone SL, et al. Physician satisfaction and burnout at different career stages. Mayo Clin Proc 2013;88:1358-67.

6. Barsoum W. Desktop medicine and physician burnout. Available online: https://consultqd.clevelandclinic. org/2017/07/desktop-medicine-physician-burnout/

7. Hallbeck MS, Lowndes BR, Bingener J, et al. The impact of intraoperative microbreaks with exercises on surgeons: A multi-center cohort study. Appl Ergon 2017;60:334-41. 
8. Wheelock A, Suliman A, Wharton R, et al. The Impact of Operating Room Distractions on Stress, Workload, and Teamwork. Ann Surg 2015;261:1079-84.

9. Bucknall V, Burwaiss S, MacDonald D, et al. Mirror mirror on the ward, who's the most narcissistic of them all? Pathologic personality traits in health care. CMAJ

Cite this article as: Bolanos MD, Zwischenberger JB. Human factors and human nature in cardiothoracic surgery. J Thorac Dis 2017;9(8):2268-2270. doi: 10.21037/jtd.2017.07.22
2015;187:1359-63.

10. Wahr JA, Prager RL, Abernathy JH 3rd, et al. Patient safety in the cardiac operating room: human factors and teamwork: a scientific statement from the American Heart Association. Circulation 2013;128:1139-69. 